\title{
AC 2012-4742: ASSISTING ADJUNCT FACULTY USING COMMITTEE EXAMS
}

\section{Dr. Randall D. Manteufel, University of Texas, San Antonio}

Randall Manteufel serves as an Associate Professor of mechanical engineering at The University of Texas, San Antonio (UTSA), where he has been on the faculty since 1997. His teaching and research interests are in the thermal sciences. He is currently the Faculty Advisor for ASHRAE at UTSA.

\section{Dr. Amir Karimi, University of Texas, San Antonio}

Amir Karimi is a professor of mechanical engineering and the Associate Dean of Undergraduate Studies at the University of Texas, San Antonio (UTSA). He received his Ph.D. degree in mechanical engineering from the University of Kentucky in 1982. His teaching and research interests are in thermal sciences. He has served as the Chair of Mechanical Engineering (1987 to 1992, and Sept. 1998 to Jan. of 2003), College of Engineering Associate Dean of Academic Affairs (Jan. 2003 to April 2006), and the Associate Dean of Undergraduate Studies (April 2006 to present). Karimi is a Fellow of ASME and Senior Member of AIAA, and holds membership in ASEE, ASHRAE, and Sigma Xi. He is the ASEE Campus Representative at UTSA, ASEE-GSW Section Campus Representative, and served as the Chair of ASEE Zone III (2005 to 2007). He chaired the ASEE-GSW section during the 1996-97 academic year. 


\title{
Assisting Adjunct Faculty using Committee Exams
}

\begin{abstract}
Many engineering programs use adjunct faculty to teach foundational courses such as thermodynamics. It is critical that adjunct instructors be mentored to ensure the course is consistent from semester-to-semester. A brief meeting in the beginning of the semester where the syllabus and textbook are shared with adjunct instructors is often inadequate. Grade distributions, coverage of material, as well as student learning outcome can vary significantly. A goal of the engineering program is to have consistency in courses. Dialogue throughout the semester is effective when full-time faculty members interact and work with adjunct instructors. Yet the dialogue needs to be purpose driven, otherwise the dialogue has been found to be anemic. To address these challenges, a committee was formed to mentor an adjunct faculty teaching a foundational thermodynamics course. The committee focused on jointly creating and grading exams. The students in the class were surveyed four times through the semester. Students were initially reticent because others would be involved in making and grading exams. However, as the semester progressed, the overall attitude of the class improved and student attitude was no different than that from other classes. The final grade distribution for the class was consistent with previous semesters. Fewer students passed the class compared with historical data for adjunct instructors. This supports the conclusion that higher pass rates from adjunct instructors are not an indication that adjuncts are better instructors where students demonstrated mastery of the material. In contrast, higher grade appear to stem from the adjuncts desire to be liked by the students and rehired by the department. Overall, the committee assisted the adjunct instructor through the preparation and grading of exams to help meet course objectives and ensure course consistency.
\end{abstract}

\section{Introduction}

Most engineering programs use adjunct (i.e., part-time) faculty to teach courses. It is the perception that programs are becoming more dependent on adjuncts to teach core undergraduate engineering courses. This is driven by increasing undergraduate enrollments, decreasing number of faculty due to budget constraints, and increasing focus on achieving or improving the "tier-1" research status of the University. The quality of the teaching performed by adjuncts varies just like that for full-time faculty. There is often the perception that adjuncts are more eager to please students, and one easy way to please students is to issue high grades. This is easy to understand since end-of-semester student surveys are often the sole mechanism by which adjuncts are evaluated. If their evaluation scores are perceived as being low, they may not be invited back to teach next semester. 
Supto ${ }^{1}$ taught for many years as an adjunct and humorously describes how adjuncts can be treated as a "pet rock" which is a near-perfect low-maintenance pet. Adjuncts typically are "off the radar screen" of the Dean and Chair, hence receive minimal feedback except from students in their classes. Adjuncts often have little authority to improve the laboratory/class they teach and may not be included in curriculum decisions. Supto recommends that "every adjunct should have a full-time faculty member assigned as an advocate and resource” but this often isn't the case $^{1}$. Adjuncts are often left to fend for themselves.

Departments and faculty may want to do an excellent job of teaching undergraduates, yet it is often the lack of resources and not the lack of knowledge, that prevents them from doing better. Some undergraduate engineering programs do an outstanding job and have shared their practices and experiences through the literature on engineering education. For example, military academies have provided insight into their program ${ }^{2}$. They describe mechanisms by which new faculty develop as instructors, such as requiring first-time instructors to audit a course for a semester as a student before teaching the course. This is designed to ensure instructors are familiar with the academic material and the department's educational goals for the course. In addition, new instructors receive feedback on their teaching performance with regular face-toface meetings with a course coordinator, committee, department chair, and/or combination of these. Classroom visits occur multiple times each semester where experienced faculty members visit the class of the new adjunct instructor. Traditional student course evaluations both at the mid-year and end-of-semester provide feedback to the instructor and the department. Programs with an emphasis on undergraduate education often have an active teaching/learning center that promotes educational excellence and is a real resource to help instructors to improve. All of these activities and mechanisms are integrated together to better meet the institution's core mission of doing an excellent job of educating students ${ }^{2}$.

It has been described that effective teaching is one that produces demonstrable results in terms of the cognitive and affective development of the student ${ }^{3}$. The main method used to assess a student's knowledge is through examination under a controlled environment. Assessment in engineering courses often boils down to seeing if the student can apply mathematical and physical principles to solve a given problem. This method of grading students is retained in this paper.

Consistency in class coverage, rigor and assessment from semester-to-semester, regardless of the instructor, is critical to consistent preparation of students for careers in engineering. As such this is often demonstrated in the ABET accreditation process ${ }^{4}$. Abnormalities in grade distributions are often an indicator that the preparation of students is being affected by the instructor teaching the class ${ }^{5}$. When grades are high, it isn't necessarily because students have done a better job of mastering the material. It isn't uncommon to find students who earned the highest grade possible in a prerequisite course, yet display little mastery of the material. Although less common, it is 
also possible that just because grades in a class are low, it isn't because students aren't learning. A course may be structured such that one bad test day dooms the student's grade for the semester. Yet this work was initiated because adjuncts were issuing much higher grade distributions that historically reasonable and it was suspected that it wasn't because of superior learning on the part of the students.

\section{Assessing Adjunct Performance}

When an instructor teaches a class, the performance of the instructor can be evaluated using a number of sources including feedback from students taking the class, peer evaluations from within the department, and final overall course grades which are often publically available.

The student feedback is almost entirely collected through end-of-semester course surveys which can have some shortcomings, such as they: typically occur before the end of the semester; don't focus on how the instructor can improve their performance; and often have low student participation when the surveys are conducted online. Student feedback can be finicky and strongly influenced by the student's most recent experience (positive or negative) in the class. The students' current perception of their grade affects their attitude. It is the goal of some faculty to give students the perception that they are "on-tract” for an "A" grade before the survey is conducted, and intentionally adjust grades downward with a tough final exam. One can sometimes detect these instructors by how strongly they oppose surveys conducted after final grades are issued. They tend to insist that the surveys be done before final exams and before final grades are issued.

The department chair is often the person who extends offers to adjunct faculty to teach classes. They may review a course portfolio or have a committee review the portfolio of adjuncts. But the primary source of input continues to be from students' teaching evaluations or complaints. When students are upset, they often complain both to the instructor and then to the department chair. When a chair receives student feedback about an adjunct, it is often negative and rarely positive.

Grades tell much about what happens in the classroom. Some adjuncts are lenient graders while some are harsh. When harsh, this often leads to student complaints. When lenient, this rarely leads to student complaints. If anything, lenient grading leads to complaints from other faculty members, especially if an adjunct is in a rotation with other faculty for the same course or students proceed into the next class lack mastery of the foundational prerequisite material. If grades bounce up-and-down from semester to semester, it is problematic for all of those teaching the course and follow-up courses. 


\section{Grade Fluctuations Motivating this Study}

The mechanical engineering degree program at authors' institution requires a two-semester course sequence in thermodynamics. The first course (Thermodynamics-I) focuses on the fundamental concepts and the second course (Thermodynamics-II) deals with the application of fundamental concepts (thermodynamic cycles, exergy, psychrometric applications, and combustion processes, etc.). Grades are monitored for many classes such as thermodynamics and faculty often discuss trends in grade distributions, especially in the context of learning and mastery of the course material. Obviously, a good knowledge of the fundamental concepts covered in Thermodynamics-I prepares students to succeed in Thermodynamics-II.

At this institution all required mathematic, science, and engineering courses must be completed with a grade of ' $C$ " or higher. Therefore, the successful attempt rate is defined as the percentage of students enrolled in the class who complete the course with a grade of either " $\mathrm{A}$ ", or " $\mathrm{B}$ " or "C". Grades of "D," "F" or "W" (withdraw from the class) are considered unsuccessful attempts. A simple metric is the percentage of students receiving grades of D, F, or W (DFW percentage).

Between fall semester 1994 and spring 2011, the first course in thermodynamics was offered 48 times ${ }^{4}$. Eight different instructors have taught the course during this period, which consisted of four tenured or tenure track (T/TT) and four none tenure track (NTT) or adjunct faculty members. The cumulative grade distributions for T/TT and NTT faculty members are compared in Table 1. Table 1 shows the number of semesters taught and the total number students for each class of instructor. Two types of grade point averages are included in Table 1 . The column identified as GPA represents the standard course grade point average, where grades of W do not have any influence on the values of GPA. The standard GPA might be misleading for the evaluation of the success rate in completing a course, since a grade of $\mathrm{W}$ still represents an unsuccessful attempt. One reason that students drop a course is that they are failing the class. To provide an alternative measurement for comparison, an adjusted grade point average (GPAW) is computed by treating a grade of " $W$ " equivalent to an " $F$ " which is being weighted as zero (0) points. The GPAW for each class or instructors are included in the last column of the Table 1.

The DFW rates among all instructors teaching the first course in thermodynamics varied between 18\% (a NTT faculty) and 64\% (a T/TT faculty). Table 1 shows that the DFW rates for T/TT faculty have been higher than those for the NTT faculty. A study tracking students from the first course into the second course in thermodynamics indicates that the passing rate in the second course in thermodynamics is higher for those students who completed the first course with the instructors who were tough graders, that is those who issued lower GPAs in the prerequisite thermodynamics class 5 . 
Table 1. Cumulative Grade distribution for sections of

Thermodynamics-I taught by each instructor.

\begin{tabular}{|l|c|c|c|c|c|c|c|c|c|c|}
\hline $\begin{array}{c}\text { Inst- } \\
\text { Type }\end{array}$ & $\mathbf{N}$ & $\mathbf{S}$ & \% A & \% B & \% C & \% D & \% F & \% W & \% DFW & $\begin{array}{c}\text { GPA } \\
\text { (GPAW) }\end{array}$ \\
\hline T/TT & 38 & 1716 & 10 & 16 & 25 & 14 & 17 & 20 & 50 & $\begin{array}{c}1.85 \\
(1.49)\end{array}$ \\
\hline NTT & 10 & 260 & 20 & 33 & 27 & 9 & 10 & 12 & 31 & $\begin{array}{c}2.38 \\
(2.09)\end{array}$ \\
\hline $\begin{array}{l}\text { T/TT } \\
\text { and } \\
\text { NTT }\end{array}$ & 48 & 1796 & 11 & 17 & 24 & 13 & 16 & 20 & 48 & $\begin{array}{c}1.93 \\
(1.55)\end{array}$ \\
\hline
\end{tabular}

Note: $\mathrm{N}=$ number of classes, $\mathrm{S}=$ number of students, $\mathrm{T} / \mathrm{TT}$ = tenured or tenure track, NTT $=$ non-tenure track.

Of the eight instructors who have taught Thermodynamics, three are still active in teaching the course. Table 2 summarizes the grade distribution for these instructors.

Table 2. Cumulative grade distributions by three different instructors still active in teaching Thermodynamics-I.

\begin{tabular}{|l|c|c|c|c|c|c|c|c|c|}
\hline Instructors & $\mathrm{A}$ & $\mathrm{B}$ & $\mathrm{C}$ & $\mathrm{D}$ & $\mathrm{F}$ & $\mathrm{W}$ & GPAW & num & DFW \\
\hline Inst-1 & 88 & 139 & 239 & 120 & 141 & 157 & 1.55 & 884 & $47 \%$ \\
\hline & $10 \%$ & $16 \%$ & $27 \%$ & $14 \%$ & $16 \%$ & $18 \%$ & & & \\
\hline Inst-2 & 52 & 81 & 102 & 71 & 38 & 126 & 1.54 & 470 & $50 \%$ \\
\hline & $11 \%$ & $17 \%$ & $22 \%$ & $15 \%$ & $8 \%$ & $27 \%$ & & & \\
\hline Inst-3 & 20 & 25 & 16 & 4 & 5 & 5 & 2.55 & 75 & $19 \%$ \\
\hline & $27 \%$ & $33 \%$ & $21 \%$ & $5 \%$ & $7 \%$ & $7 \%$ & & & \\
\hline
\end{tabular}

The first two instructors who are T/TT faculty have taught the class 17 and 13 times respectively while the third instructor who is a NTT has taught the course 3 times with class sizes of 27, 21 and 27 students. The statistics for the first two instructors are surprisingly similar for the distribution of grades as well as the cumulative GPA and failure rate. The course fail rate is the last column in the table and is the percentage of students earning grades of D, F, or W. The third instructor has been awarding higher grades on the average. Students talk and share recommendations on instructors, especially as they decide which classes to take or avoid taking. Some students are quick to take courses from instructors who are easy graders and some will delay taking the course when taught by instructors who issues lower grades. 


\section{Exam Committee}

Recently, Instructor-3 was asked to teach the thermodynamics-I course and the faculty agreed to work together to explore ideas to improve the consistence of the class, especially through coverage of the course material and rigor of exams. In the past, course material, textbooks, exams, and detailed syllabus were shared with adjunct faculty with the idea that it will help maintain consistency in the course. But sharing information without meaningful follow-up is anemic. Little interaction occurred between the instructors after the beginning of the semester. The two T/TT faculty who taught the class most often teamed with the adjunct faculty assigned to teach the class for a fourth time. All three were eager to work together as a committee with the goal of enhancing consistency. The mechanism by which the consistency was to be improved was not clear from the onset.

The first task of the committee was a careful review of the syllabus where each lecture was planned before the semester started. Because Instructor-3 (adjunct instructor) had taught the course before, the schedule didn't change much except increasing the number of days to the coverage of entropy and the $2^{\text {nd }}$ law of thermodynamics. This is where many students have difficulty in the course. The instructor had his own opinions about class grading, homework schedule, and the use of pop quizzes during the semester. These appeared standard mechanisms to assess student progress and are good ways to encourage students to keep-up-to-date. It was agreed that the instructor would use these mechanisms and the committee didn't try to persuade the instructor to adopt a different grading scheme. It was agreed that exams provided the best mechanism to ensure course consistency.

It was agreed that two mid-term exams and a final exam would be jointly written and graded by the committee. The committee would meet a week before the scheduled exam and discuss what problems would be selected. Each member was responsible for one problem for the midterms and two problems for the final exam. There was much discussion in the face-to-face meetings centered on which problems to select. The problems were thoroughly reviewed to ensure the material had been sufficiently covered in the lectures so that the problems would be "fair". The wording of the problems was carefully crafted to be consistent with the wording used in the textbook. As much as possible, the exam problems were like the homework problems but not copies of homework problems. Before the exam, the solution was provided by the problem's author.

During the semester, all exams were closed-book. Students were provided with several pages of equations containing all the necessary formulas to solve textbook problems. The equations sheet was distributed at the start of the semester in order for students to be familiar with them before the exam. Students were not allowed to add notes to the equation sheets. In addition to the 
equation sheets, students had access to all thermodynamic property tables in the appendix section of the textbook.

\section{Lessons Learned}

A number of lessons were learned through this experience and are shared here.

\section{Lesson \#1 Exams Can’t be Too Long}

The first lesson the committee learned was that the first exam was too long for the 50 minute class period. Too many students didn’t finish the exam. This was discussed by the committee after the exam and it was agreed that it was too long. For future exams, the instructor for the class would time himself taking the exam and use that result to adjust the exam length as needed. It was decided that the instructor should be able to complete the exam within $50 \%$ of the time allotted for each exam. For both the second midterm and the final exam, the initial drafts were deemed too long using this method. Hence they were shortened during the editing process. It should be emphasized that the committee's opinion was not unanimous concerning the length of the exams. Some believed the exams didn't need to be so short and preferred longer exams. Nevertheless, the exams were shortened with the intent that the average student had sufficient time to solve all the problems.

\section{Lesson \#2: The Instructor is Responsible}

After the first exam, it became clear that the committee was advisory and final decisions had to be made by the "instructor of record" who was responsible for the exams and overall grades. Students were initially apprehensive that exam problems were being made by faculty who had reputations for being more demanding. Students asked questions like "What if the exams don't match the lectures?” and "Why doesn't the instructor make the exams?” It was discussed and agreed that the committee was advisory and the instructor of record (the adjunct instructor) would make all the final decisions.

This issue became very practical after the first exam when students complained that the exam was too long and the instructor decided to adjust the exam grades to compensate. The other committee members recommended against adding points to everyone's score, and favored giving students the opportunity to "earn” extra points. A number of suggestions were made, like allowing students to rework the exam (as if it were homework) and submit their corrected exams within a week to earn extra points. The instructor felt that the alternatives presented for the first exam were not practical. He believed that if students were given an option of reworking problems at home for additional credit, it would leave the door open for some students to copy from each other. If he used class time to allow students to rework the exam, it would interfere with the class schedule. The instructor decided to add 15 points (out of 100 point exam) to everyone's score. This resulted in several students receiving more than 100 points for the first exam. 
Lesson \#3: A Learning Community

Another lesson was that everyone learned from this experience, not just the students. Only one example is discussed in this paper and it involves cheating. It was suspected by some on the committee that a few students cheated on the first exam. This was shared with the instructor, but no specific recommendations were given to the instructor on how to deter or catch cheaters. The expectation was that the instructor would look for cheating on the next exam. The instructor assured the committee that he never left the room during the exam, he watched students during the exam, he saw nothing suspicious, and he doubted there was cheating. He would however, check for cheating on the next exam. It should be noted the course had an enrolment of 90 students in a room of about 130 capacity, so the seating increased the chance of students looking at their neighbors' paper and coping their solution.

In retrospect, the instructor had a simple idea where three versions of the exam were developed and randomly distributed to the class, since students were sitting next to each other during the exam. The only difference was that a few numbers were changed. Although simple, this had not been used by other committee members to catch cheaters. One committee member had used this approach only for quizzes involving True/False and multiple choice questions. After the exam, two students were found to have correct answers but for the wrong version of the exam. The evidence was overwhelming.

The previous year, one of the committee members had presented a charge of scholastic dishonesty for cheating on an exam through the Office of Student Judicial Affairs. The charge stated:

"[name of student] was observed to be looking at the papers of adjacent students during the exam on [date]. The instructor observed this repeatedly during the exam and asked the Teaching Assistant (TA) [name] to watch for the same. The TA state he observed the same behavior before being asked by the instructor. [Student] was allowed to finish the exam uninterrupted and was confronted by both instructor and TA after the exam.”

This case was resolved by the student "not disputing the alleged violation" and accepting the faculty disposition which was a "written warning". But the interaction between the student, TA and faculty was very unpleasant since the student repeatedly claimed there was "no evidence" of cheating. This was an example of where multiple exams would have provided hard evidence.

Many instructors, however, are reluctant to press cases of academic dishonesty against students for several reasons. One reason is this process can be time consuming as it requires the instructor to confront the student with the alleged charge, submit a report to the Office of Student Judicial Affairs, and attend a hearing, if student requests such a hearing. Also, a record of the 
infraction (if proved) will be retained by the Office of Student Judicial Affairs and this type of information may be requested for background information for students applying for jobs requiring security clearances. Regardless of why, after the committee members reviewed the evidence, the instructor decided not to pursue the matter. This was a surprise for the other committee members, yet it points back to Lesson \#2. There was no plausible mechanism by which the other faculty could force the instructor to press charges against the students involved in scholastic dishonesty.

\section{Lesson \#4: Logistics are Difficult}

A surprising lesson is that the logistics of creating common exams, reviewing them, revising them, and grading them is much more difficult that initially expected. Every aspect of working together required more time than what was initially envisioned. Shared grading of the exams was especially difficult. The point distribution for each problem was decided before the exam, so that wasn't a source of difficulty. The challenge was circulating the $\sim 90$ exams for grading. The protocol was that the instructor checked-in each exam, and sorted them into folders based on the exam version. The envelopes were given to another who had a few days to grade and circulate to the other committee member.

After the second midterm, a serious problem developed when the instructor found that four exams were missing. All other exams were returned to the class, except the four "lost" exams which had a negative effect on the attitude of the class. This was quickly developing into an embarrassing situation for everyone, especially for the two faculty members not teaching the class, yet as it was initially reported that the exams had to been lost in one of their offices. After a few days of panic and frantic cleaning of the offices, the instructor found that the "lost" exams were mixed with the exams from another class in the instructor's office. The lost exams had never been lost while being circulated to the committee for grading. The prospect of losing exams prompted much regret and second-guessing from the other committee members for having become involved in the process. The committee was formed voluntarily and represented additional work for all involved with little prospect for meaningful recognition by the department, college or university.

In addition, the final exam logistics are surprisingly difficult since this is a rushed time period of the semester. For a midterm exam, it is acceptable to return the exams after a week. But the grading of the final exam had to be done within one day by each of the committee members, with little flexibility allowed because there were only a few days between the exam time and when final grades were due. The other committee members had their own classes and own final exams to both administer and grade. So this was a very hectic time to circulate and grade the exams. 


\section{Lesson \#5: Committee Exams Require Trust}

There are many ways that instructors can manipulate a grading system and make it look like students are more capable than they may be. For example, instructors can "broadcast" to the class what will be on the next exam by working "select" problems, especially during a review for the exam. This was a concern with the committee since exam problems were finalized days before the exam is given, and it is conceivable that the instructor could have "targeted reviews". Happily, there was no evidence that the exams were compromised in this way. The problems were based on textbook problems which everyone on the committee agreed that students should be able to solve. Overall, the exams were considered to have been given with integrity and a few of the students should have been able to make 100/100 (i.e., perfect) scores.

\section{Grading Exam Problems}

Committee members were responsible to grade their own problems selected for each exam. For the two midterm exams (50 minute exam), each committee member graded at least one problem. For the final exam (150 minutes exam), initially six problems were select which included two problems from each committee members. However, after the instructor solving the suggested problems for the exam, he determined that the exam was too long. Therefore, he eliminated two of the problems (his own selected problems). The exam problems were selected and designed to assess students' knowledge of the fundamental concepts. Typically, each problem was divided into several parts in order for students to receive partial credits. For example the following problem was one of the four problems on the final exam:

Ammonia enters a valve as saturated liquid at 9 bar (state 1 ) and undergoes a throttling process to a pressure of 2 bar (state 2 ).

a) Simplify the first law and the second law of thermodynamics for this process. 7 points

b) Evaluate $h_{2}$ and $s_{2}$ for this process. 7 points

c) Is this process internally reversible or irreversible? You must justify your answer. 6 points

For this problem several students started with wrong equations for the first and second laws of thermodynamics as applied to a control volume (open system). Therefore these students received no partial credit for the part (a). However, if students start with correct equations, they received partial to full credit depending how many correct terms were eliminated from the equation.

The average score for the final exam was lower than those for the midterms. The lower average scores could be attributed to several factors:

1. The final exam covered entropy analysis and the second law of thermodynamics. Our experiences indicate that students have more difficulty with this topic. 
2. The topics covered in thermodynamics are closely interrelated. Solving problems involving newer topics require full knowledge of topics covered in earlier chapters. For, example in evaluation of the power produced by a turbine, students must distinguish the system as open or closed, apply the correct equations for the first and second laws of thermodynamic, simplify these equations appropriately, and use correct values for thermodynamic properties. Those students who do not study on the regular basis or solve homework assignments find the subject more difficult and confusing.

\begin{abstract}
Assessment
It was decided to assess the impact of this activity using two mechanisms: student surveys during the semester and evaluation of final course grades.
\end{abstract}

Four surveys were conducted: at the beginning of the semester, after the first mid-term exam, after the second mid-term exam, and with the final exam (last page of the final exam). The number of students participating in the surveys was: 55, 77, 55 and 56 students. The course had 90 students enrolled. The first three surveys were conducted at the end of a 50-minute lecture period. The surveys were designed to be anonymous and no students were identified by name. The last survey was attached to the final exam, so students turned in the survey at the same time they turned in the final exam. They were asked to separate the survey from the exam and not sign it so that it was anonymous. The participation rate was influenced by the class attendance on that day. Students were asked to select one of five possible responses:

SD (strongly disagree) D (disagree) N (neutral) A (agree) SA (strongly agree)

Fifteen survey questions were asked:

Q1 You are willing to participate in this survey.

Q2 You attend all the lectures.

Q3 You read the textbook on a regular basis.

Q4 You do all the homework.

Q5 You study on a regular basis.

Q6 You study with other students.

Q7 You use an organized approach when solving problems.

Q8 The textbook is helpful.

Q9 Lectures are helpful.

Q10 Homework is graded fairly.

Q11 Quizzes are graded fairly.

Q12 Exams are graded fairly.

Q13 You will earn an "A" in this class. 
Q14 You are treated fairly in this class.

Q15 You enjoy this class.

The questions from the first survey were changed because of confusion associated with the wording of the statements. In particular, students were asked for responses to:

"You will earn an "A" in this class"

"You will earn at least a "C" in this class".

A significant faction of the students ( $20 \%$ ) were more confident they would earn an "A" than they would earn at least a "C". This points out the truth that survey questions need to be simple and direct, otherwise they can easily be miss-understood. The survey questions were revised to keep the question simple and direct, as shown above.

Results from the surveys are shown in Fig. 1. A numeric value of 1 to 5 was assigned for responses SD to SA. The average class response was calculated for each question. Then a slope was determined based on the four responses for each question. The questions were then sorted based on this slope. For example, question 13 was: "You will earn an "A" in this class". The averages are 3.3, 2.9, 2.7 and 2.5, which had the strongest decrease throughout the semester. It appears students were initially more optimistic about earning an " $\mathrm{A}$ " at the beginning of the class, but after the mid-term exams their expected grade was lower hence they are less optimistic about earning an "A". After the final exam, only 5 of the 56 respondents "strongly agreed" with this statement. 


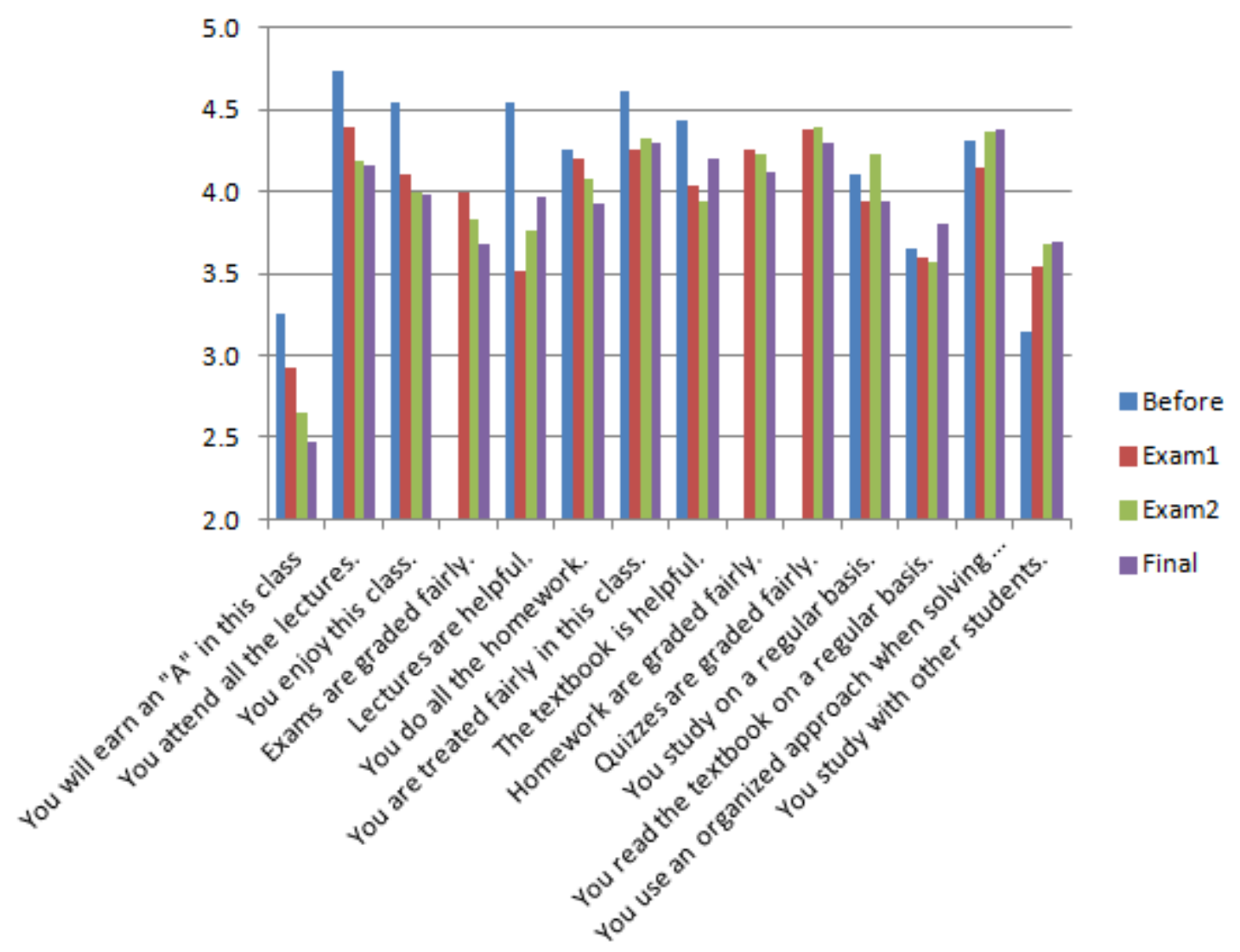

Figure 1. Results from student surveys in Thermodynamics class.

On the other extreme, the Question \#6: "You study with other students” had the greatest positive increase over the semester. The average response changed from 3.1, 3.5, 3.7 to 3.7. In addition, modest increases are associated with statements concerning: studying regularly, reading the textbook, and organized problem solving. All of these are strongly encouraged by instructor because they are effective at helping students pass the course. The response to the statement "You attend all the lectures" was disheartening since it showed what students were less diligent in attendance as the semester progressed.

The responses to "you enjoy this class" decreased over the semester; however, the response to "You are treated fairly in this class" was relatively constant over the semester. Overall, the response from students was not negatively influenced by the way exams were conducted.

Students had the opportunity to write comments on the surveys. Most of the comments were positive. It was hoped to select some of the student's written comments to support a trend or consensus from the class. However, student comments are highly variable. For example, on the final survey, one student wrote: “test was a joke”. By some faculty, this was assumed to mean it was "very easy". But the instructor for the class interpreted the comments as saying that the final exam as "impossibly difficult". It is uncertain the intended meaning of this student's comment. 
Another student wrote: "Only complaint is that tests appear to different material worked on in class or homework assignments given." In this case, the student probably found the exams too hard. Comments on the instructor ranged from "Great instructor, very helpful” to the opposite "Sorry but the lectures were very dull despite interesting material." Overall, there was little consensus from the comments. No comment on the final exam complained that the exams were unfair because other faculty were involved in creating and grading the exams. In contrast, a comment after the first exam was: "I'm not a big fan of quizzes and exams being written and graded by other teachers if it takes longer for them to grade and return. Also as I'm sure they are very familiar with the curriculum, they are not familiar about how much time we spend on each topic. They could end up giving us an exam question in a format we have not seen. Like the past exam." This was probably the most direct comment directed at how exams were being prepared and graded. A number of inconsistencies are in the student's comments, since quizzes didn't involve the committee and the problem format was specifically chosen to be consistent with the textbook. The wording of problems can be confusing to students, that is why the exam wording is often "word-for-word" from problems found in the textbook. This type of comment appears almost every semester, regardless of the instructor. But no consistent outcry was directed toward the exams.

Final course grades are very important. After the first exam, there was no "curving" of the second exam nor of the final exam. It was strongly believed the exams were fair and the average student had sufficient time to work the problems. The sources on the exams and especially the final exam were disappointingly low. As a result the grade distribution for the semester was more consistent with previous semesters, as shown in Fig. 2.

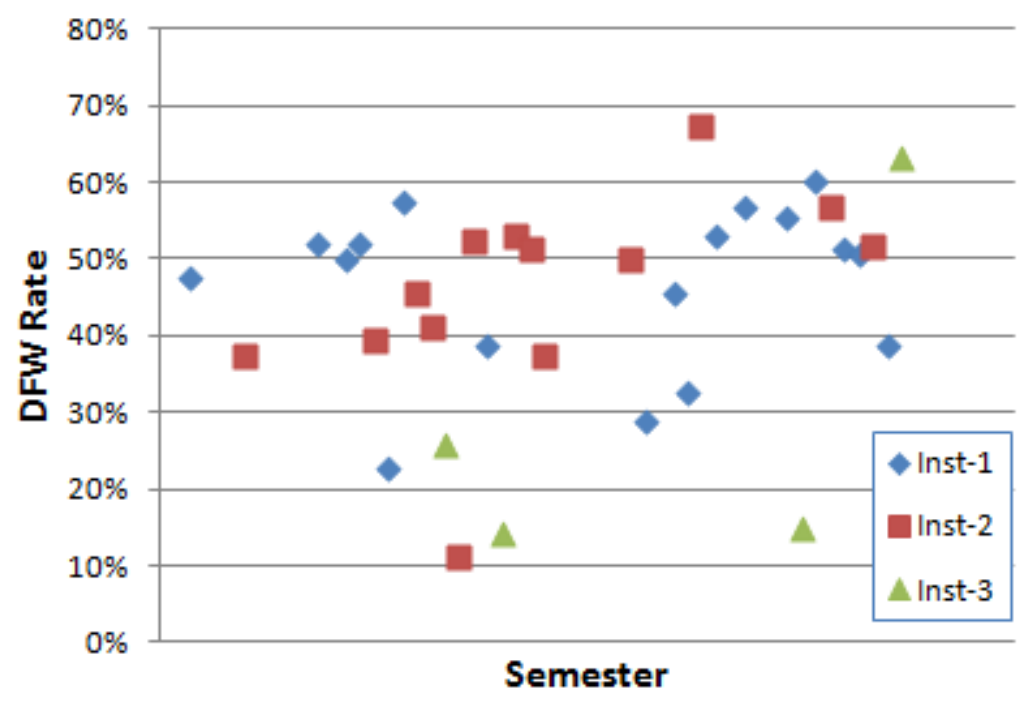

Figure 2. Percentage of class earning D, F or W grades. 
The details for the semester are shown in Table 3, showing the grades earned. The class GPA was 1.11 which is considered very low. Of the 90 students enrolled, $36 \%$ passed the class. This is a higher than average failure rate. About $37 \%$ of the class was repeating the class. There isn't much statistical difference between those taking the class for the first time and those repeating the class, except possibly a slightly higher number of "A" grades given to first time takers. Of the 4 A's earned, $75 \%$ were earned by those attempting the class for the first time

Table 3. Grade distribution for Thermodynamic I class with committee exams.

\begin{tabular}{|l|l|l|l|l|l|l|l|l|l|}
\hline Instructor & $\mathrm{A}$ & $\mathrm{B}$ & $\mathrm{C}$ & $\mathrm{D}$ & $\mathrm{F}$ & $\mathrm{W}$ & GPAW & num & DFW \\
\hline Inst-3 & 4 & 8 & 21 & 18 & 21 & 18 & 1.11 & 90 & $63 \%$ \\
\hline & $4.4 \%$ & $8.9 \%$ & $23.3 \%$ & $20.0 \%$ & $23.3 \%$ & $20.0 \%$ & & & \\
\hline
\end{tabular}

It should be noted that instructor-3 gave open book exams when he taught the course for the first two times. In addition he commented that he was giving higher partial credit in the past than the partial credit given by other two committee members who graded some of the exam problems this semester. Instructor-3 indicated that he seldom gave less than $50 \%$ credit on a problem. His rationale is that if the student makes an attempt to solve the problem, they should get something. He has given up to $75 \%$ credit for a problem if a student solved half of the problems correctly. In discussions, it was found that there are significant differences between the grading philosophies of the instructors and this is the greatest source of difference in the final grades issued in a class. The work of a "C" student in the eyes of one instructor could as easily be an "A" or " $\mathrm{F}$ " in the eyes of another instructor.

\section{Summary}

Overall, the committee was effective at improving consistency in the coverage and rigor of the material. This consistence is reflected in the material covered on the exams and on the overall grade distribution for the class. There were many observations made during the process. As the system evolved, two of the faculty viewed the exams as being very simplistic and should be viewed as "minimum competency" exams. The instructor, however, viewed the exams as possibly being too rigorous. The exam problems were not "tricky", because everyone on the committee debated what problems would be used and the exams were carefully picked to give sufficient time for the average student. The problems were often decided with comments like: "if they can't solve this problem, they shouldn't pass the class". Although it is common practice to have course coordinators or committees to ensure course coverage and consistency, it is far too common to see grade distributions bounce up-and-down from semester-to-semester depending on the instructor. Overall, having a committee make and grade exams has been found to be effective at improving the consistency of course coverage and grades. 


\section{References}

1. Sputo, T., Care and Feeding Instructions for Engineering Adjunct Faculty, Journal of Professional Issues in Engineering Education and Practice, 17, 2006.

2. Pocock, J.B and S.T. Kuennen, "Developing Civil Engineering Faculty”, Session 2793, Proceedings of ASEE Annual Conference, 2003.

3. Gosink, J., “Optimizing the Effectiveness of Adjunct Faculty,” ASEE-IEEE Frontiers in Education Conference, pg 610-624, 1994.

4. $\quad$ ABET www.abet.org 2011.

5. Karimi, A. and R. Manteufel, “Are Grades Good Indicators of Students’ Depth Knowledge?” Proceedings of ASEE Conference, 2012. 